\title{
DESCRIÇÃO DE ALGUNS INSTRUMENTOS SIMPLES UTILIZADOS PARA A COLETA E CONCENTRAÇÃO DE ELEMENTOS FÓSSEIS DE PEQUENAS DIMENSÕES DE ORIGEM ARQUEOLÓGICA OU PEDOLÓGICA*
}

Questões de natureza metodológica são comuns a qualquer disciplina nas mais diversas áreas de conhecimento científico. Tais questões, entretanto, se apresentam mais amiúde quanto mais nova for a aplicação de uma disciplina em particular.

A necessidade de definição de uma metodologia específica para estudos antracológicos no Brasil nos conduziu à idealização e construção de diferentes instrumentos, os quais finalmente se provaram bastante simples e de extrema utilidade nos trabalhos de campo.

A iniciativa deste artigo surgiu a fim de descrever este equipamento à comunidade científica, uma vez que ele pode ser útil não só para a amostragem de carvões, como também de diversos outros elementos fósseis de pequenas dimensões, provenientes de contexto tanto arqueológico quanto pedológico.

Os trabalhos de campo, realizados entre os meses de julho e dezembro de 1995, estão relacionados a uma tese de doutorado desenvolvida pela segunda autora, objetivando o estudo antracológico de sambaquis do Estado do Rio de Janeiro. Estes estudos visam a obtenção de informações sobre evolução paleoambiental, assim como sobre a utilização da madeira pelas populações pré-históricas. Estudos antracológicos são praticamente inéditos no Brasil, e em meios tropicais de uma maneira geral. A antracologia, disciplina que começou a ser desenvolvida na década de 60 , principalmente em regiões temperadas e mediterrâneas, se baseia na determinação de fragmentos de carvão a partir de sua estrutura anatômica, a anatomia da madeira sendo muito bem conservada após combustão.

Uma boa amostragem de material destinado a estudos antracológicos, seja ela realizada em sítios arqueológicos ou em perfis pedológicos, de-

(*) Trabalho desenvolvido em associação com o projeto "Aproveitamento Ambiental das Populações Pré-Históricas do Estado do Rio de Janeiro", um convênio MN/FINEP/ FUJB. pende da coleta de grandes quantidades de sedimento, a fim de obter-se um número suficientemente importante de fragmentos de carvão que permita a interpretação correta dos dados obtidos, seja com referência ao paleoambiente e ao paleoclima, seja quanto à utilização, pelo homem, do meio vegetal.

No caso presente, duas estratégias principais foram abordadas: amostragem de perfis e, quando possível, coleta de material antracológico concomitante à escavação do sítio.

$\mathrm{Na}$ amostragem de perfis, cada amostra, ou nível de coleta, corresponde, de modo geral, a $1 \mathrm{~m}^{2}$ de superfície por $10 \mathrm{~cm}$ de espessura (ou seja, 100 litros de sedimento compactado). Em um perfil de $5 \mathrm{~m}$ de altura, por exemplo, seja ele arqueológico ou pedológico, o volume de sedimento coletado chega a 5000 litros, podendo alcançar muito mais, se for levada em conta a descompactação.

Neste trabalho, foi feita uma coleta padrão em perfis em todos os sítios amostrados, compreendendo seções de $2 \mathrm{~m}$ de comprimento por $50 \mathrm{~cm}$ de profundidade e $10 \mathrm{~cm}$ de espessura. Normalmente, é difícil manter os níveis horizontais e de espessura constantes, em particular no caso de sedimentos que são, na maior parte das vezes, heterogêneos. Para isso, idealizamos uma "guia de coleta", simples de construção e de utilização, que permite a realização de amostragens seguindo camadas regulares.

Devido ao enorme volume de sedimento coletado, é praticamente impossível fazer o transporte de tais quantidades do local de coleta ao local de estudo, de modo que uma primeira concentração deve ser feita diretamente no local de coleta. Esta se faz por peneiragem, a seco ou na água, e para facilitar esta operação foi elaborado um "suporte de peneira" simples e facilmente transportável.

No caso da antracologia, em particular, os elementos a serem concentrados (carvões) são de pequenas dimensões e muito leves. Sua capacidade de flutuação é frequentemente aproveitada, em diferentes estudos antracológicos, para separar es- 
tes elementos do material mais pesado (Badal et al. 1989: 9; Figueiral 1992: 193). As "células de flotação" utilizadas na Europa, no entanto, utilizam em geral equipamentos mais dispendiosos, como bombas de recuperação da água ou de injeção de ar comprimido (Buxo 1991: 107; Chabal 1989: 54). Em nosso caso, elaboramos uma "célula de flotação" bastante simples, mas que permitiu uma agilidade considerável na triagem do material, quando se pode dispor de uma fonte de água corrente. Esta operação pode ser feita no laboratório, após uma primeira peneiragem a seco.

Estes três equipamentos são descritos a seguir, de modo a permitir a arqueólogos, antracólogos ou cientistas de outras disciplinas, eventualmente interessados, sua fabricação e utilização.

\section{Guia de amostragem de perfis sedimentares}

Este aparelho, de extrema simplicidade, é constituído de uma barra tranversal e de dois montantes verticais. Foi confeccionado em alumínio, tendo como objetivo servir de guia para a decapagem horizontal do sedimento do perfil a ser amostrado (Fig. 1a e 1b).

A barra transversal ("régua") tem $2.7 \mathrm{~m}$ de comprimento por $2 \mathrm{~cm}$ de largura, sendo dividida em três segmentos (respectivamente 100, $70 \mathrm{e}$ $100 \mathrm{~cm}$ ), para maior facilidade no transporte. No momento de utilização os três segmentos são fixados um ao outro com 4 parafusos ("borboletas"), de modo a constituir uma régua rígida de $2.5 \mathrm{~m}$ de comprimento. A $25 \mathrm{~cm}$ de cada extremidade da régua, uma ranhura transversal delimita a zona de amostragem ( $2 \mathrm{~m})$. Uma série de 6 furos equidistantes, de $5 \mathrm{~mm}$ de diâmetro, posicionados ao longo de $20 \mathrm{~cm}$ em cada extremidade da régua, permite o seu posicionamento sobre os montantes verticais.

Os montantes são constituídos por duas barras em forma de $\mathrm{U}$, medindo $152 \mathrm{~cm}$ de comprimento por cerca de $3 \mathrm{~cm}$ de seção. Em cada montante foram fixados 16 parafusos de $4 \mathrm{~mm}$ de diâmetro, espaçados de $10 \mathrm{~cm}$, o primeiro e o último estando situados a $1 \mathrm{~cm}$ de cada extremidade. Quatro orifícios de $10 \mathrm{~mm}$ de diâmetro (dois em cada

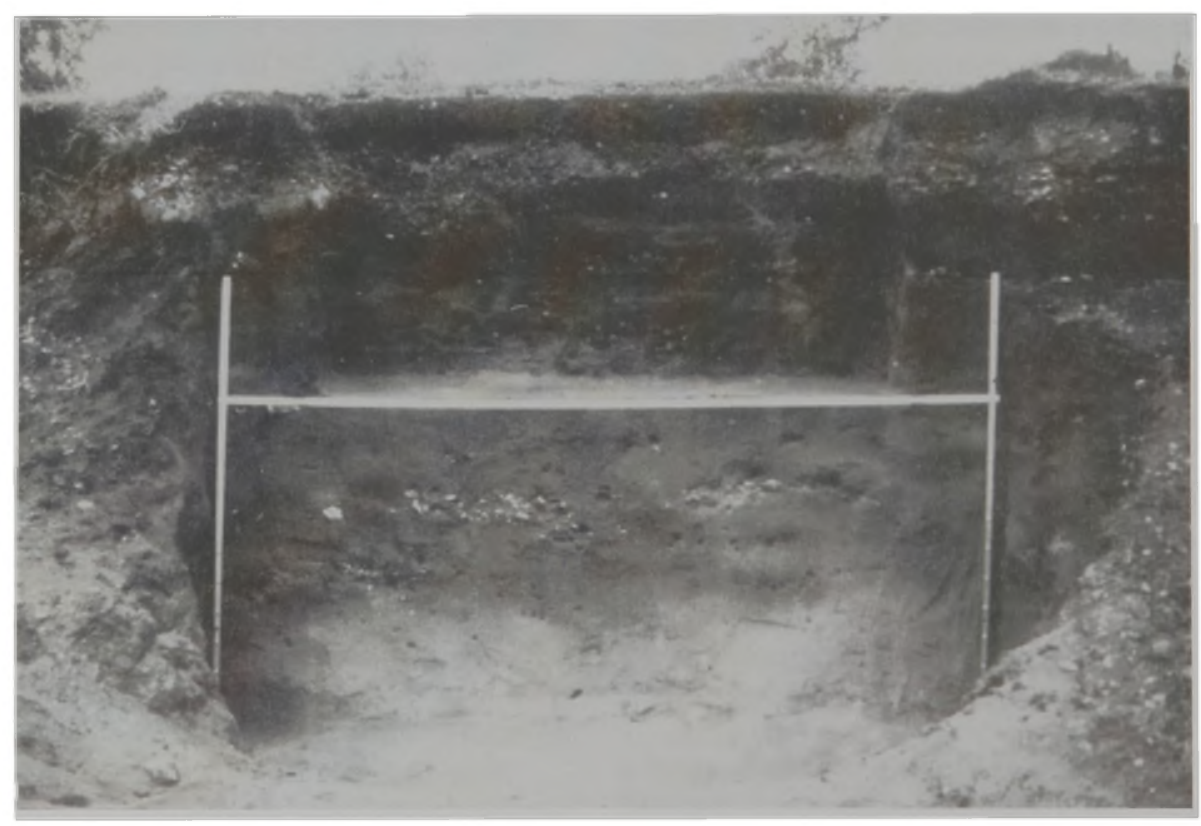

Fig. 1a - Guia de amostragem de perfis sedimentares. Sambaqui Salinas Peroano (Cabo Frio, Estado do Rio de Janeiro). 


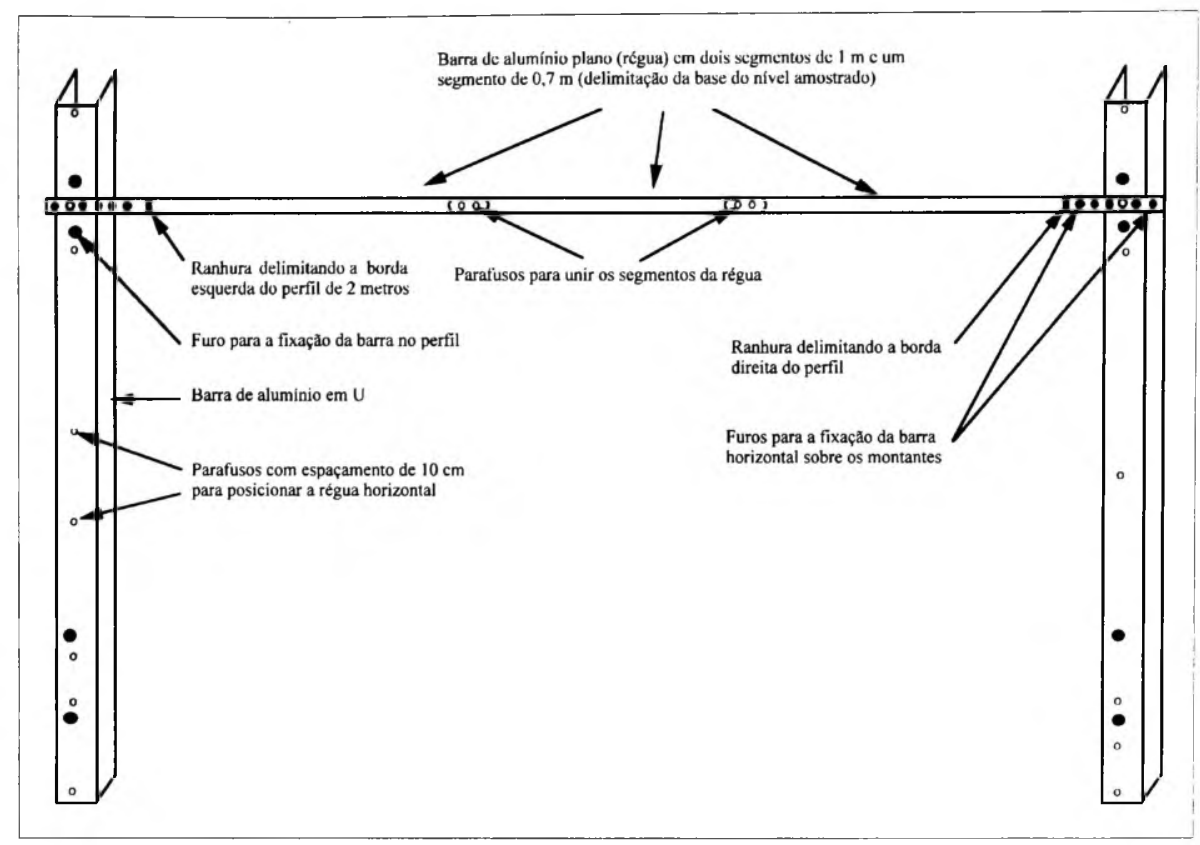

Fig. 1b-Guia de amostragem de perfis sedimentares.

extremidade), situados entre os parafusos, permitem a fixação dos montantes no perfil.

Antes da fixação do equipamento, a fim de obter um resultado adequado, é indispensável preparar bem o perfil a ser amostrado. Para isso deve ser feita uma decapagem cuidadosa, de modo a obter uma superfície perfeitamente vertical em toda a altura do perfil, ao longo de pelo menos $2.50 \mathrm{~m}$ de largura. Um dos montantes será então fixado contra a parede em posição vertical e cravado no sedimento de modo a nivelá-lo com a superfície do perfil, utilizando-se para isso ponteiros de $8 \mathrm{~mm}$ de diâmetro por 15 a $20 \mathrm{~cm}$ de comprimento. $O$ segundo montante será então posicionado, com a ajuda da régua colocada horizontalmente, e em seguida fixado como o primeiro. Ao colocar a régua em posição horizontal, sobre o primeiro par de parafusos situado imediatamente sob a linha superficial do terreno, poderá ser feita uma primeira decapagem (limpeza), destinada a obter-se uma superfície plana horizontal, utilizando a régua como guia. Ao posicionar, em seguida, a régua nos parafusos inferiores, poder-se-á proceder às decapagens sucessivas de camadas de $10 \mathrm{~cm}$ de espessura (amostragem propriamente dita).

\section{Suporte de peneiras}

Este instrumento foi utilizado para peneiragem dos sedimentos na água, seja diretamente numa lagoa, seja com o auxílio de um jato de água (mangueira de jardim).

Constitui-se de três pés em tubo metálico, de cerca de $80 \mathrm{~cm}$ de comprimento, sobre os quais foram soldados 2 seções de tubo de cerca de $3 \mathrm{~cm}$ de comprimento, espaçadas de $25 \mathrm{~cm}$, e de dois aros de ferro (em vergalhão) de $55 \mathrm{~cm}$ de diâmetro, sobre os quais foram soldados, de modo equidistante $\mathrm{e}$ perpendiculares ao plano dos aros, 3 pinos de cerca de $4 \mathrm{~cm}$ de comprimento e de seção ligeiramente inferior ao diâmetro interno dos tubos (Fig. 2).

Para a utilização, os pinos dos anéis são encaixados nas seções dos tubos soldadas nos pés; as peneiras são colocadas sobre os anéis. A peneira superior serve para recuperar o material mais grosseiro, enquanto a peneira inferior, de malha mais fina, serve para recuperar o material de menores dimensões. A lavagem é feita versando-se água sobre a peneira superior com o auxílio de um jarro ou de uma mangueira de jardim. Os carvões retidos sobre as peneiras são em seguida recuperados ma- 


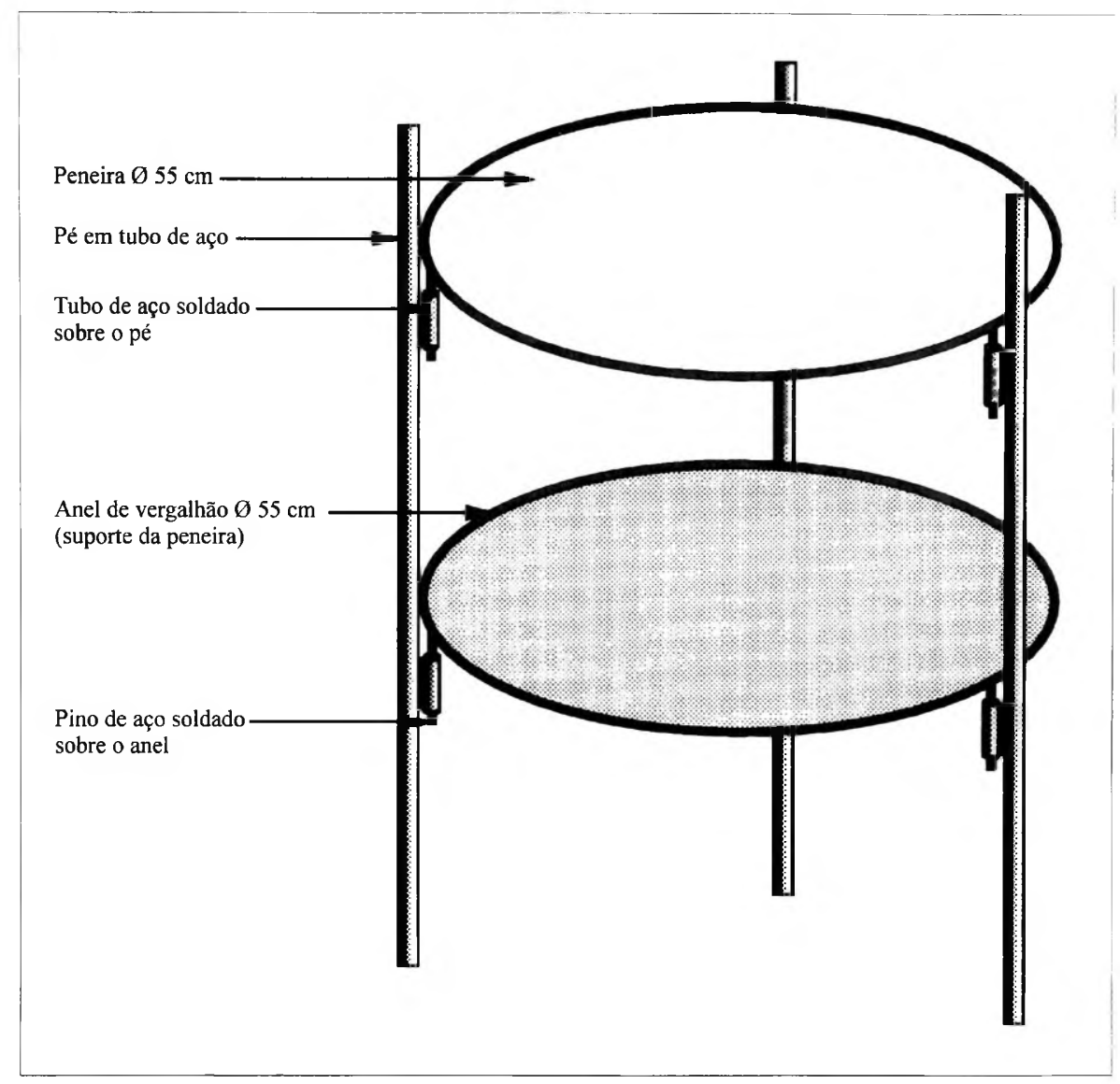

Fig. 2 - Suporte de peneiras (tripé).

nualmente com uma pinça flexível (triagem) e secados ao ar livre.

Em todas as fases do trabalho, foram utilizadas peneiras de dimensão padrão encontradas no comércio (casas de material de construção). A malha de peneiragem ideal para este tipo de estudo sendo de $4 \mathrm{~mm}$, estas foram as mais utilizadas (peneiras "feijão"). Eventualmente, na necessidade de separar o material mais grosseiro para facilitar a triagem, associamos a estas peneiras de malha $6 \mathrm{~mm}$ (peneiras "café"). No caso contrário, em que nos interessava coletar elementos de frações inferiores, associamos às peneiras $4 \mathrm{~mm}$ outras de malha $2 \mathrm{~mm}$, estas últimas conhecidas no comércio como peneiras "arroz" Em todos os casos, optamos por peneiras de aro de $55 \mathrm{~cm}$ de diâmetro.

\section{Célula de flotação}

A célula de flotação aqui descrita foi utilizada tanto para a lavagem de material proveniente da amostragem de perfis quanto de coletas concomitantes à escavação do sítio.

Os sedimentos tratados foram de natureza essencialmente arenosa, argilo-arenosa, argilosa ou constituídos de conchas, e os resultados obtidos se revelaram muito satisfatórios na maioria dos casos. Tivemos problemas apenas no caso de concreções calcárias, onde os carvões estavam impregnados de material mineral e, em consequiência, não flutuaram.

$O$ princípio de funcionamento da célula é bastante simples. Cơnsiste em lavar o sedimento, previamente depositado sobre uma peneira submersa numa cuba, em uma corrente de água turbilhonante. 
Os carvões, liberados do sedimento, são levados à superfície da água e em direção à periferia da cuba, caindo sobre uma peneira plástica de malha fina onde os elementos sólidos são recuperados ("peneira de recuperação").

$O$ corpo da célula é constituído de uma metade de tonel de plástico espesso, de forma cilindrotroncocônica, de altura de cerca de $60 \mathrm{~cm}$ e de diâmetro interior de cerca de $57 \mathrm{~cm}$ na parte cilíndrica, reforçado por um perfil de alumínio na borda superior (Figs. 3, 4, 5, 6 e 7).

$O$ fundo do tonel foi reforçado internamente por uma placa de alumínio de forma cônica com o objetivo de provocar um movimento giratório da massa d'água, o que tem como consequência colocar o sedimento em movimento e favorecer, desta forma, a liberação dos carvões. O fundo do cone e do tonel são atravessados por um tubo em PVC de $1 " 1 / 2$ de diâmetro, rosqueados interiormante, fechados por rolha.

Esta abertura situada no fundo da cuba permite a recuperação do material fino que passa através das peneiras, o que pode ser feito, eventualmente, após cada lavagem. A abertura é utilizada igualmente para esvaziar a célula após utilização.

Uma chegada de água foi colocada lateralmen- te, logo acima do cone de alumínio, de forma a permitir a adaptação de um esguicho de água de diâmetro padrão de 3/4" e, no exterior, de uma mangueira de jardim flexível. A abertura do esguicho e sua orientação são reguláveis, possibilitando a otimização da pressão e do movimento turbilhonante.

Um anel metálico, fixo a $5 \mathrm{~cm}$ acima da chegada de água, serve de suporte a um quadro em alumínio sobre o qual é colocada a peneira (malha de $4 \mathrm{~mm}$ ). Eventualmente, pode-se utilizar uma série de duas peneiras superpostas. $O$ quadro é constituído de 4 barras de alumínio de $1 \mathrm{~cm}$ de largura, encaixadas em retângulo e cujos ângulos foram cortados para oferecer uma maior superfície de apoio (Fig. 7).

A $270^{\circ}$ da entrada de água foi feita uma abertura retangular de $5 \mathrm{~cm}$ de largura por $10 \mathrm{~cm}$ de altura, cuja base se situa a $10 \mathrm{~cm}$ acima da peneira e a $3 \mathrm{~cm}$ do bordo superior do tonel. De cada lado desta abertura, no interior do tonel, foi fixada uma corrediça de cerca de $2 \mathrm{~cm}$ de largura (Figs. 6 e 7) na qual foi inserida uma placa que, ao ser regulada verticalmente, permite a modificação da distância entre a peneira e a saída de água. No exterior do tonel foi colocada uma calha cujo objetivo é diri-

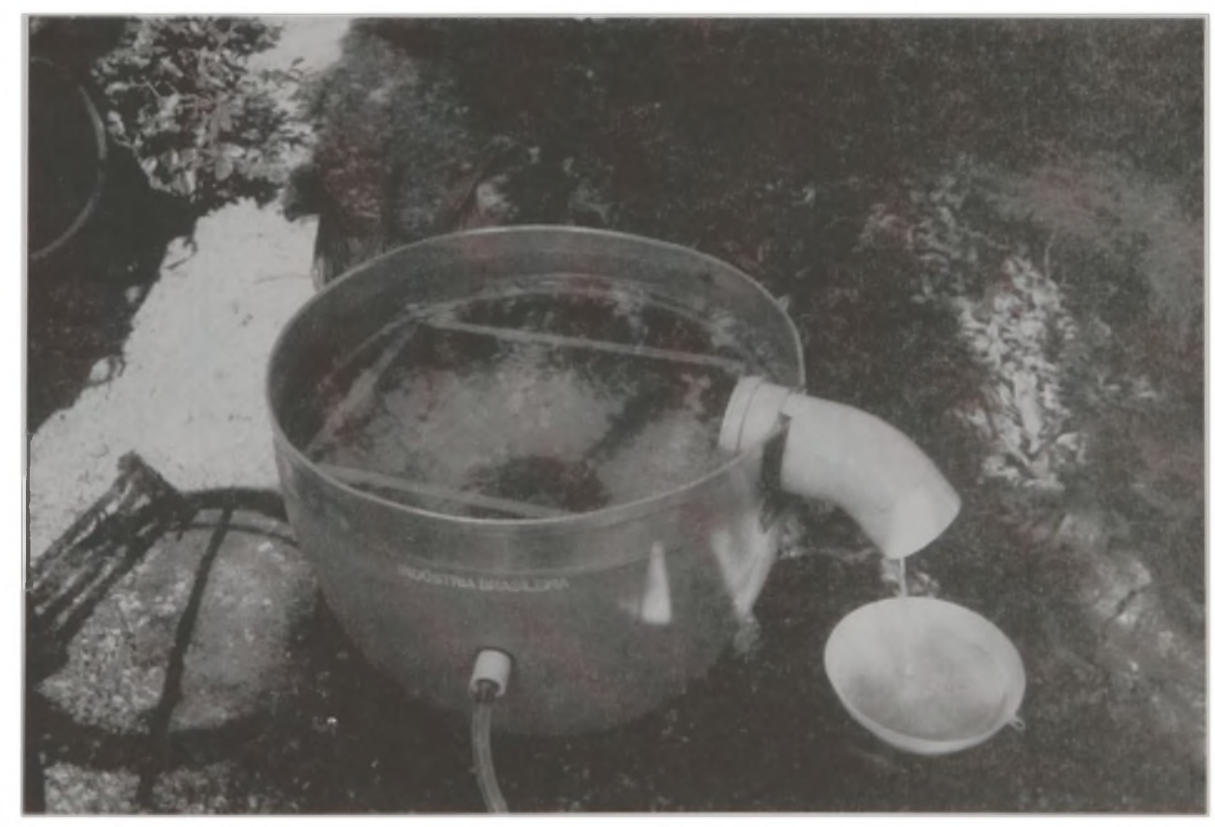

Fig. 3-Cédula de flotação. 
Notas - Rev. do Museu de Arqueologia e Etnologia, São Paulo, 7: 181-189, 1997.

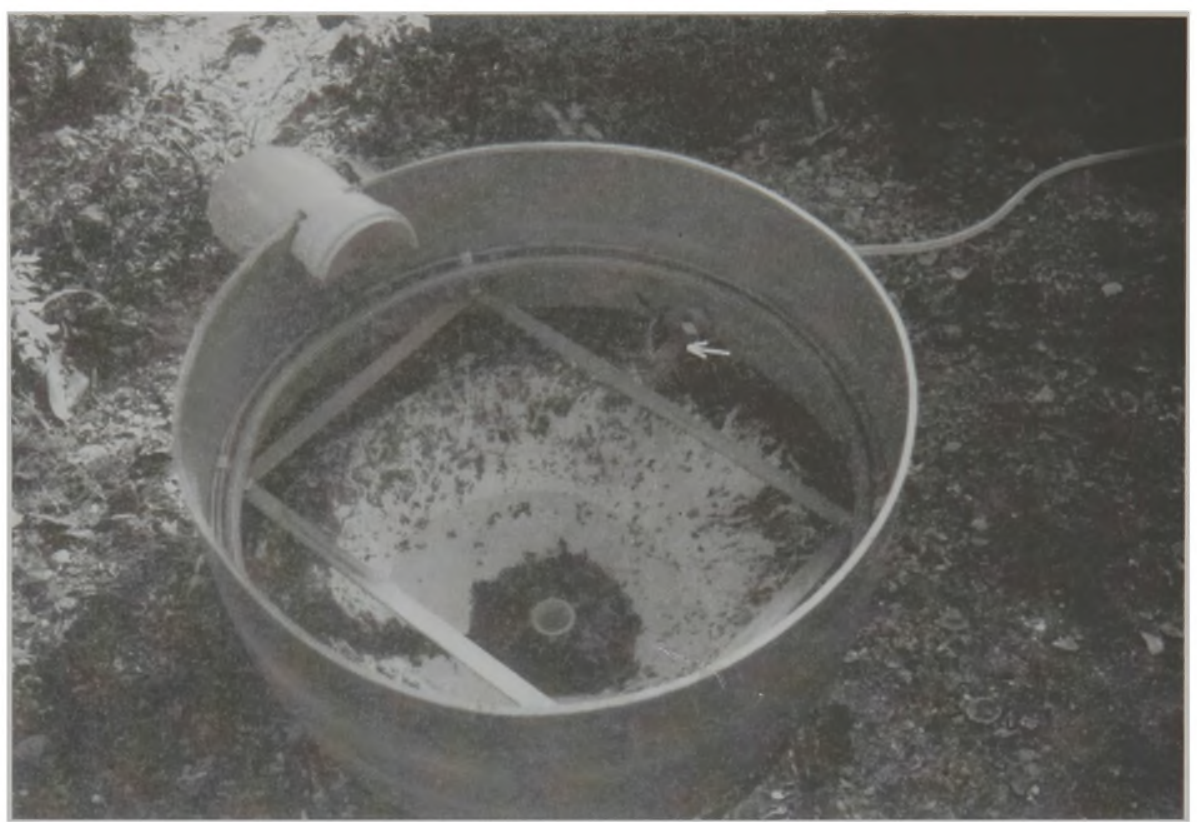

Fig. 4 - Cédula de flotação: visão de cima, mostrando a entrada de água (flecha).

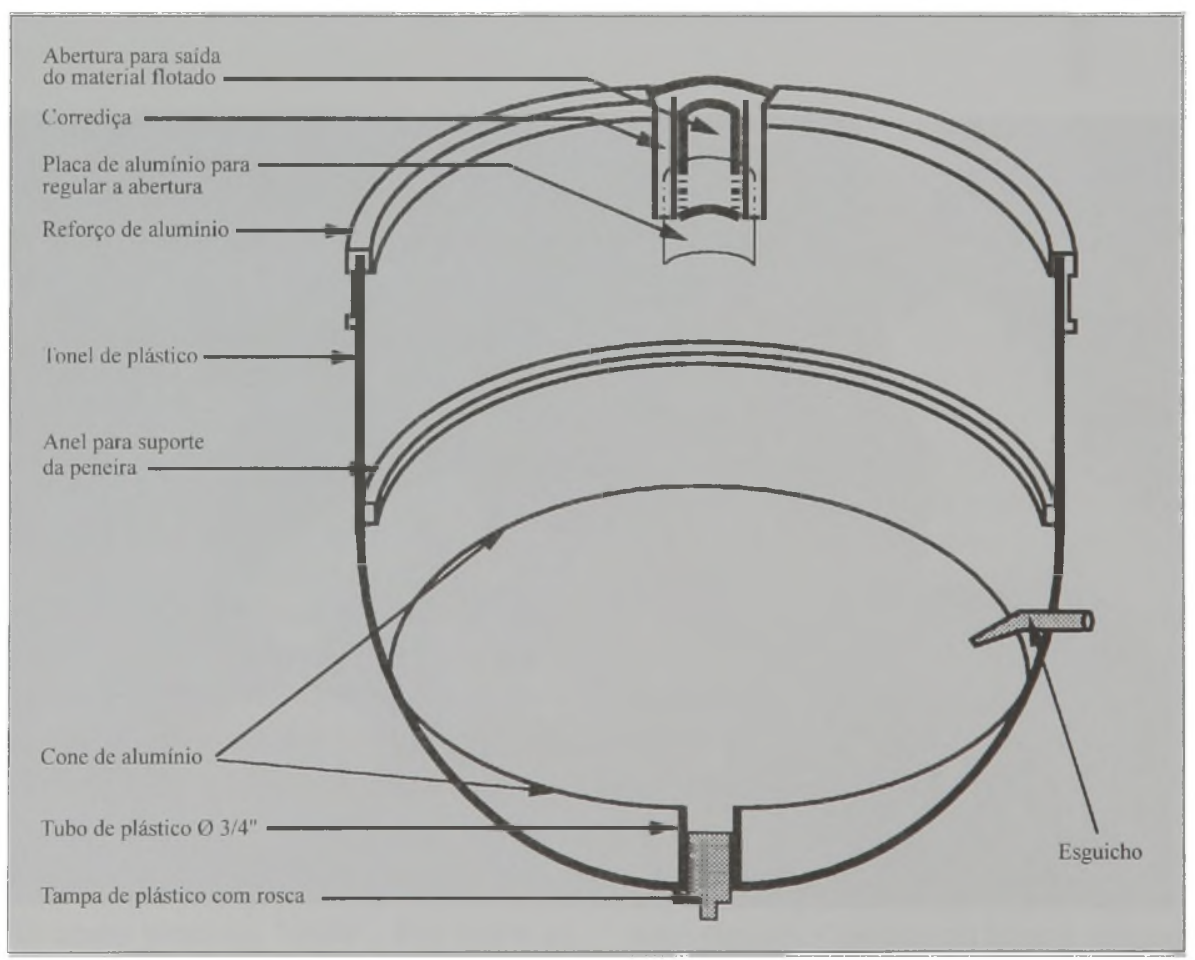

Fig. 5 - Célula de flotação: corte esquemático longitudinal pela entrada de água. 


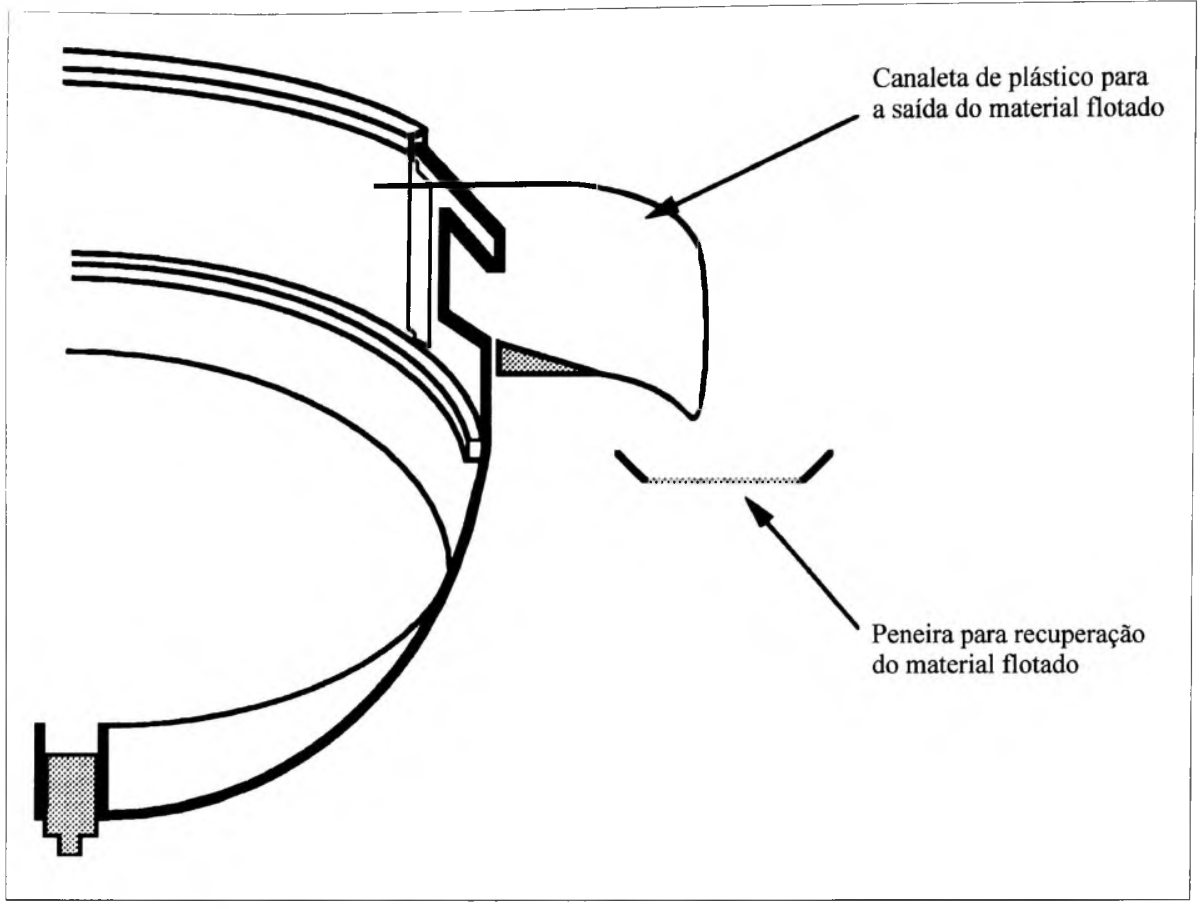

Fig. 6 - Célula de flotação: corte esquemático longitudinal pela saída de água.

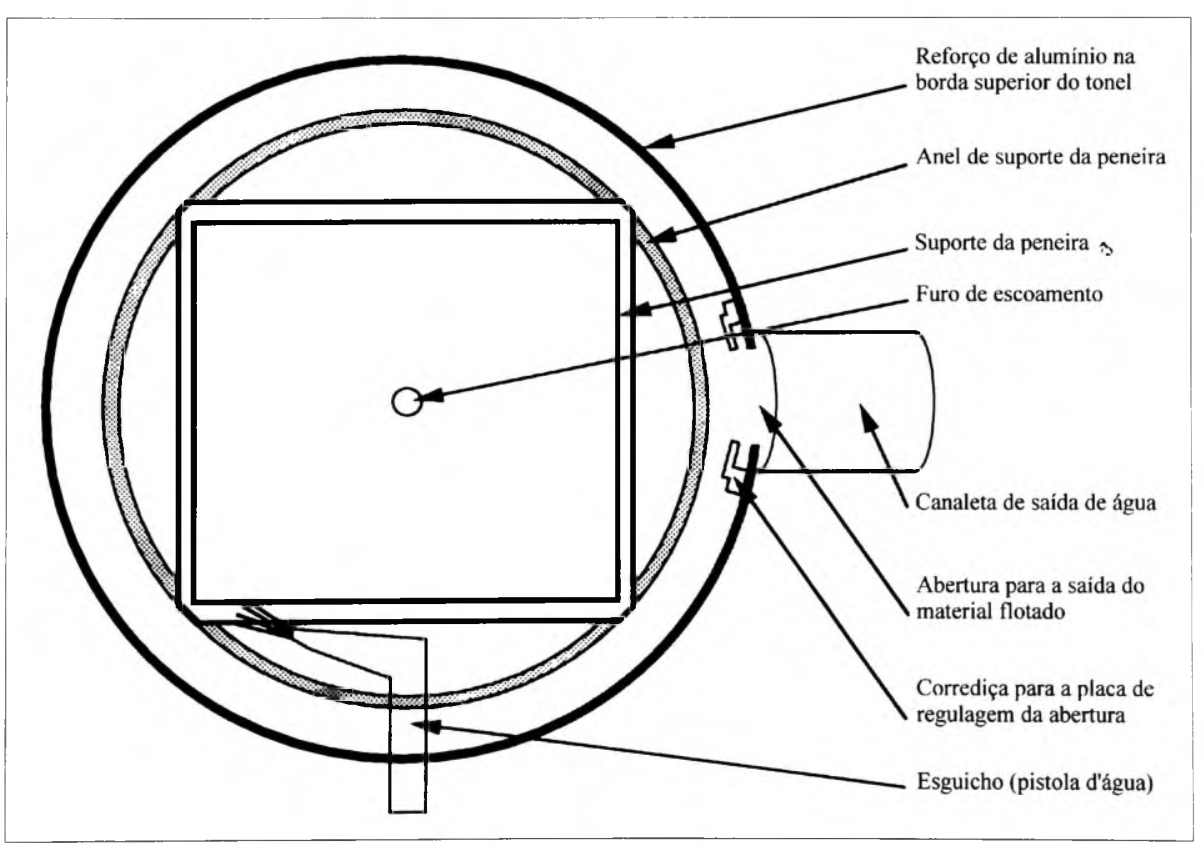

Fig. 7 - Célula de flotação: visão superior em projeção vertical. 
gir a água e o material flotado sobre a peneira de recuperação.

A célula é colocada sobre um tripé fabricado em ferro de vergalhão (Fig. 8), de diâmetro de cerca de $40 \mathrm{~cm}$.

No momento da utilização, o sedimento é depositado, em pequenas quantidades, sobre a peneira e, eventualmente, remexido com as mãos para facilitar seu movimento inicial. O material mais fino passa através das malhas da peneira e se deposita no fundo do tonel; o material mais leve (carvões e outros elementos vegetais, frequentemente ossos) flutua e é levado em direção à abertura pelo fluxo contínuo de água; o material pesado permanece na peneira (cascalho grosseiro, conchas de moluscos, lítico, cerâmica etc.), podendo ser recuperado após a flotação para servir de estudo a outras disciplinas.

No caso de ser necessária a recuperação de todo ou parte do material depositado no fundo do tonel, isto é possível em se retirando a rolha da base após cada flotação. É também possível a colo- cação de uma peneira sob esta abertura para recuperar uma fração determinada do sedimento.

\section{Agradecimentos}

Os autores agradecem a Henrique Duda, que construiu o protótipo da célula de flotação; a Lúcia Pangaio, que nos incentivou a aprimorar o equipamento, assim como a escrever este artigo; e a toda a equipe de trabalhadores que nos acompanhou no campo e contribuiu nos testes metodológicos e no aperfeiçoamento do material, dentre os quais somos particularmente reconhecidos a Fábio Carlos Batista Borges.

Jean-Pierre Ybert* Rita Scheel** Maria Dulce Gaspar***

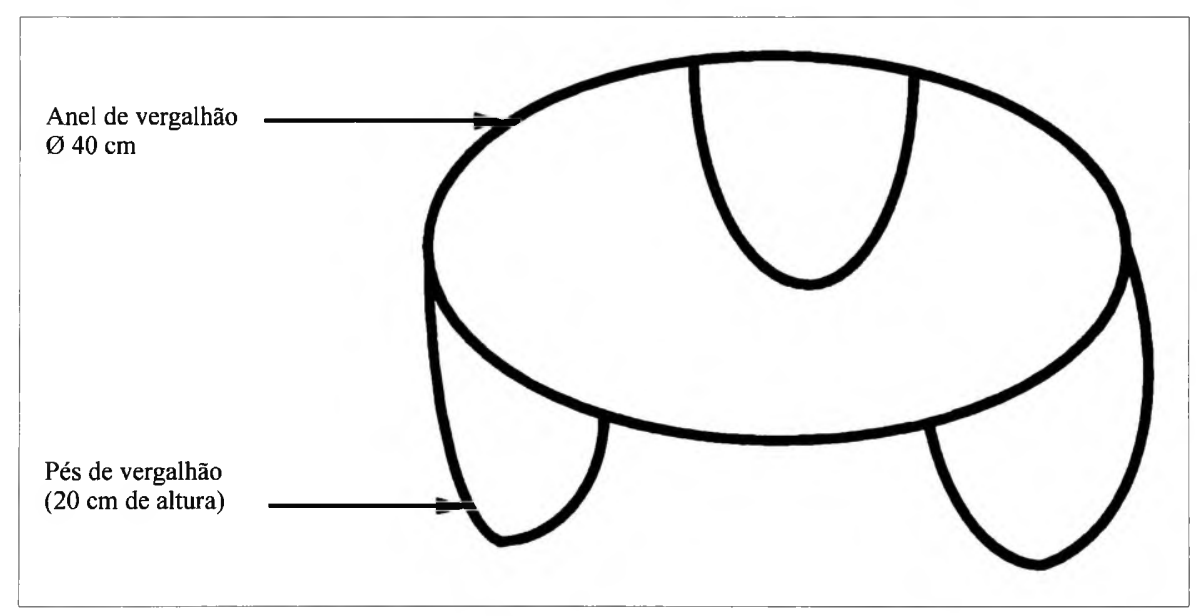

Fig. 8 - Suporte da célula de flotação.

(*) ORSTOM, France.

(**) Laboratoire de Paléobotanique, Environnement et Archéologie, Institut de Botanique. Université de Montpellier II, France. Depto. de Antropologia do Museu Nacional da Universidade Federal do Rio de Janeiro.

(***) Depto. de Antropologia do Museu Nacional da Universidade Federal do Rio de Janeiro. 


\section{Referências bibliográficas}

BADAL, E.; FIGUEIRAL, I.; HEINZ, C.; VERNET, J.-L.

1989 Charbons de bois archéologiques méditerranéens: de la fouille à l'interprétation. Acta Interdisciplinaria Archaeologica, 7: 7-22.

\section{BUXÓ I CAPDEVILA, R.}

1991 Echantillonnage et enregistrement des prélèvements. Lattara, 4: 101-114.

Recebido para publicação em 15 de abril de 1996.
CHABAL, L.

1989 Perspectives anthracologiques sur le site de Lattes (Hérault). Lattara, 2: 53-72.

FIGUEIRAL, I.

1992 Méthodes en anthracologie: étude de sites du Bronze final et de l'âge du Fer du nord-ouest du Portugal. Bull. Soc. bot. Fr., Actual. bot., 139 , 2/3/4): 191-204. 